Article

\title{
Experimental Study on Corrosion and Mechanical Behavior of Main Cable Wires Considering the Effect of Strain
}

\author{
Fangyuan $X u^{1}{ }^{1}$, Yuanli Chen ${ }^{1}$, Xianglong Zheng ${ }^{2}$, Rujin Ma ${ }^{3}$ and Hao Tian ${ }^{1,2, *}$ \\ 1 Zhejiang Institute of Communications, Hangzhou 311112,China; xfyalla@163.com (F.X.); \\ yuanli@zjvtit.edu.cn (Y.C.) \\ 2 Zhejiang Provincial Key Lab for Detection and Maintenance Technology of Road and Bridge, \\ Hangzhou 311305, China; zxl_jky@163.com \\ 3 Department of Bridge Engineering, Tongji University, Shanghai 200092, China; rjma@tongji.edu.cn \\ * Correspondence: th@zjvtit.edu.cn; Tel.: +86-159-6718-2803
}

Received: 14 January 2019; Accepted: 27 February 2019; Published: 5 March 2019

\begin{abstract}
To study the corrosion degradation of cable wires in a bridge's life, this research work created an accelerated corrosion test device, which sought to identify an optimal constant strain level. An accelerated corrosion test was carried out and the corroded specimens were scanned using super depth 3D microscopy technology. Mass loss and minimum cross-sectional diameter was measured to understand the degradation characteristics of cable wires at variable strains and corrosion time. The variation of elastic modulus, yield load, and ultimate load of corroded wires, subjected to a tensile test, were analyzed. The experimental results illustrate that the average mass loss ratio of the corroded cable wires increases nonlinearly as corrosion time increases. The higher the stress level, the more serious the corrosion level. The minimum cross-sectional diameter has good correlation with corrosion time and stress level. The elastic modulus of wires does not change significantly with the increase of corrosion time. Yield load and ultimate load decreases with the increase of strain level, and the rates of decline under different strains are nonlinear.
\end{abstract}

Keywords: main cable wire; strain effect; super depth 3D microscopy technology; minimum sectional diameter; yield load; ultimate load

\section{Introduction}

High-strength steel wires play a pivotal role in the construction of modern large-span suspension bridges. However, over time, the wires in the main cable corrode and degrade, causing safety hazards. Addressing this corrosion has become a hot issue in the engineering field worldwide.

Scholars across the globe have carried out various experimental researches on the issue-from atmospheric exposure tests in natural environments [1] to accelerated corrosion tests in artificially simulated scenarios [2-4]. The issues of concern include the effects of external temperature [5], relative humidity [6], $\mathrm{pH}$ value [7,8], ion concentration [9], and integrity of the corrosion resistant coating [10] on the corrosion of steel wires. Since the stress of the main cable in suspension bridges is generally between $500 \mathrm{MPa}$ and $600 \mathrm{MPa}$, researchers have studied the effects of strain levels on corrosion rate. Test results by Barton [11] and Nakamura [12,13] show that tension has little effect on steel corrosion, while a test by Li [14] and Yang [15] show that strain levels can accelerate the corrosion rate of steel wire. Recently, Wu [16] conducted an experiment that confers steel wire a high level of accuracy in the amount of stress applied, and demonstrates that stress levels have a significant effect on stress corrosion cracking. A critical part of these experimental studies was to ensure that the high-strength steel wire maintained a high-level strain accurately for a prolonged 
period. Quantitative approaches used to assess the corrosion degree of high-strength steel wires include electrochemical methods (for measuring parameters such as natural corrosion potential [17] and polarization resistance [18]) and physical methods (for measuring physical quantities such as diameter and mass). New methods such as optical fiber grating technology [19], ultrasonic sensing technique [20], scanning electron microscope [21], X-ray computed tomography [22], and ultra-depth 3D microscopy technology provide novel ways and ideas for corrosion feature characterization.

In terms of the mechanical properties of corroded wires, a large number of tensile tests were conducted to obtain empirical conclusions about strength, elastic modulus, and elongation. Vehovar [23] applied tensile testing of corroded steel wire on an actual bridge to estimate the strength of the steel wire with the corrosion rate. A test by Liu [24] showed that strength degradation of the steel strand increases as the corrosion degree increases, and strength decreases by three quarters after two-and-a-half years of exposure. The experimental results of an artificial climate simulation test [25] and an electrochemical acceleration test [26] conducted show a nonlinear relationship between the ultimate strength and corrosion rate of steel strands.

In this paper, an accelerated corrosion test of high-strength steel wires under a constant strain was carried out. Scanned by using ultra-depth 3D microscopy technology, the corrosion degradation law of high-strength steel wires in the main cable was studied with different strain levels and corrosion times. Static tensile tests were performed to explore the correlation between the corrosion degree and mechanical properties of cable wires.

\section{Accelerated Corrosion Test of Cable Wires with Constant Strain}

\subsection{Material and Specimens}

In order to be consistent with actual engineering practice, the high-strength steel wire used in the test was purchased from the main cable supplier of Xihoumen Bridge (Jiangsu Fasten Steel Cable Co.,Ltd, Jiangyin, China). Composition of the steel wire specimen was $0.78 \mathrm{C}, 0.22 \mathrm{Si}, 0.75 \mathrm{Mn}, \mathrm{P}<0.025$, $\mathrm{S}<0.025, \mathrm{Cr}<0.2, \mathrm{Cu}<0.2$, and its nominal diameter was $5.25 \mathrm{~mm}$.

Two parameters were considered in the test, namely, strain level and corrosion time. A total of 16 sets of high-strength steel wire corrosion tests were designed. Each set contained three test specimens. The designed conditions of these specimens are shown in Table 1 . Since the strain of the main cable in the actual operation is roughly between $2000 \mu \varepsilon$ and $3000 \mu \varepsilon$, the test considered four strain levels that could be in line with the actual strain condition of steel wires. Corrosion time was set from 1 to 4 days, a total of four time scales.

Table 1. Composition of specimens.

\begin{tabular}{cccccc}
\hline \multirow{2}{*}{ Specimens Items } & \multicolumn{4}{c}{ Corrosion Time/Day } \\
\cline { 2 - 5 } & $0 \mu \varepsilon$ & $0-1-1(/ 2 / 3)^{1}$ & $0-2-1(/ 2 / 3)$ & $0-3-1(/ 2 / 3)$ & $0-4-1(/ 2 / 3)$ \\
\hline \multirow{3yyyy}{*}{ Strain level } & $1000 \mu \varepsilon$ & $1000-1-1(/ 2 / 3)$ & $1000-2-1(/ 2 / 3)$ & $1000-3-1(/ 2 / 3)$ & $1000-4-1(/ 2 / 3)$ \\
\cline { 2 - 5 } & $2000 \mu \varepsilon$ & $2000-1-1(/ 2 / 3)$ & $2000-2-1(/ 2 / 3)$ & $2000-3-1(/ 2 / 3)$ & $2000-4-1(/ 2 / 3)$ \\
\cline { 2 - 5 } & $3000 \mu \varepsilon$ & $3000-1-1(/ 2 / 3)$ & $3000-2-1(/ 2 / 3)$ & $3000-3-1(/ 2 / 3)$ & $3000-4-1(/ 2 / 3)$ \\
\hline
\end{tabular}

${ }^{1}$ The specimen number is in the form of "strain value-corrosion time-number of parallel tests".

\subsection{Precise Strain-Holding Device}

Unlike the grip of ordinary steel bars, high-strength steel wire suffers from wedge sliding and insufficient gripping force owing to its small diameter, which makes it difficult to sustain constant strain for a prolonged period. In previous researches [9,27], a wedge-type anchorage was often used to maintain design stress. In the preliminary trial phase of our test, we adopted a three-piece wedge to hold a strain of high-strength steel wire, as shown in Figure 1. During the accelerated corrosion 
test, however, the galvanized anti-corrosion coating on the surface of the steel wire was found to have gradually become soft, thus causing a phenomenon of wedge sliding. The longitudinal displacement of the wedge-type anchorage resulted in quick attenuation of the high strain. Therefore, the preliminary trial using the wedge-type anchorage was abnegated.

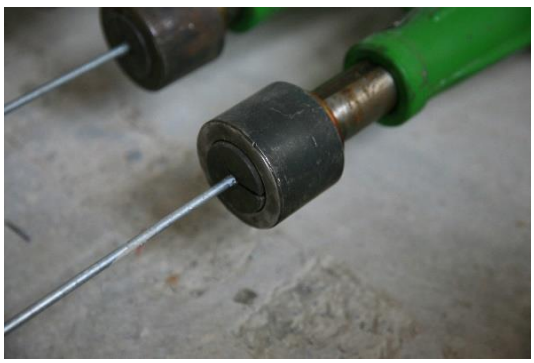

(a)

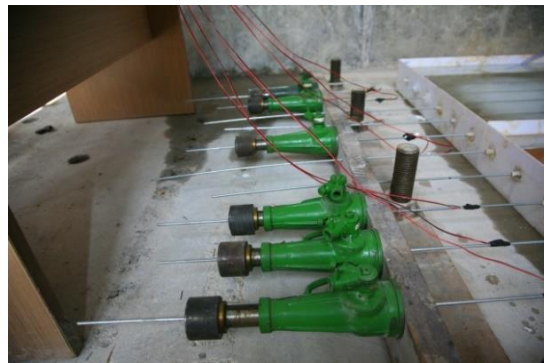

(b)

Figure 1. Strain-holding device based on wedge-type anchorage: (a) Specialized three-piece wedge anchorage for $5.25 \mathrm{~mm}$ wire; (b) perforated hydraulic jack to hold a strain.

To prevent the wedge from slipping, cold-drawn wires were fixed to the anchorage with button heads. At the same time, a constant strain to the steel wires was applied by hydraulic jack and steel shims. The accelerated corrosion device to test high-strength steel wires was divided into five components, namely, strain-holding part, corrosion tank, current loop, steel wire, and $\mathrm{NaCl}$ solution, as shown in Figure 2. In the top part of the strain-holding section, high-strength steel wires were stretched to the target strain by a jack, and a steel shim was inserted into its back. By jamming the button head, the target strain was expected to stay as is, and then the jack was removed. Figures 3 and 4 show the front and back strain-holding sections, respectively.

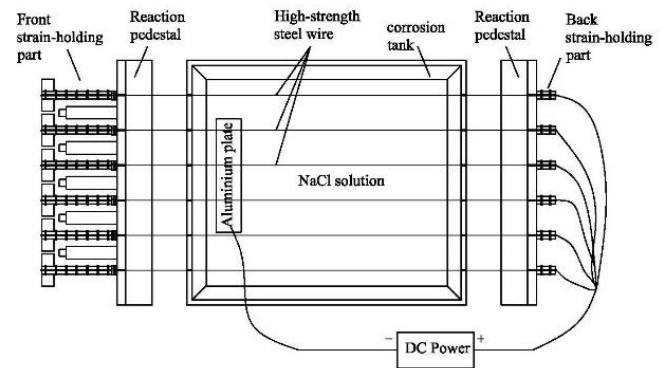

(a)

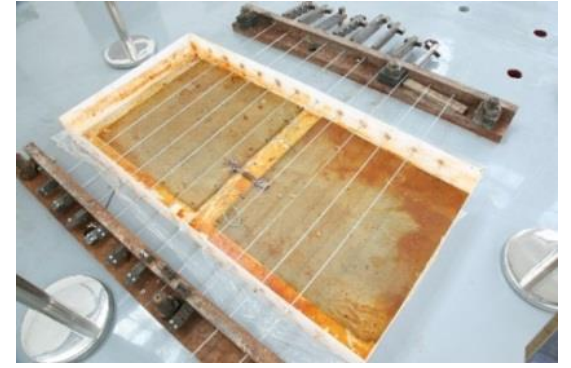

(b)

Figure 2. Diagram of the electrochemical accelerated corrosion device with high-tensile strain holding: (a) schematic diagram of the device; (b) actual experiment device.
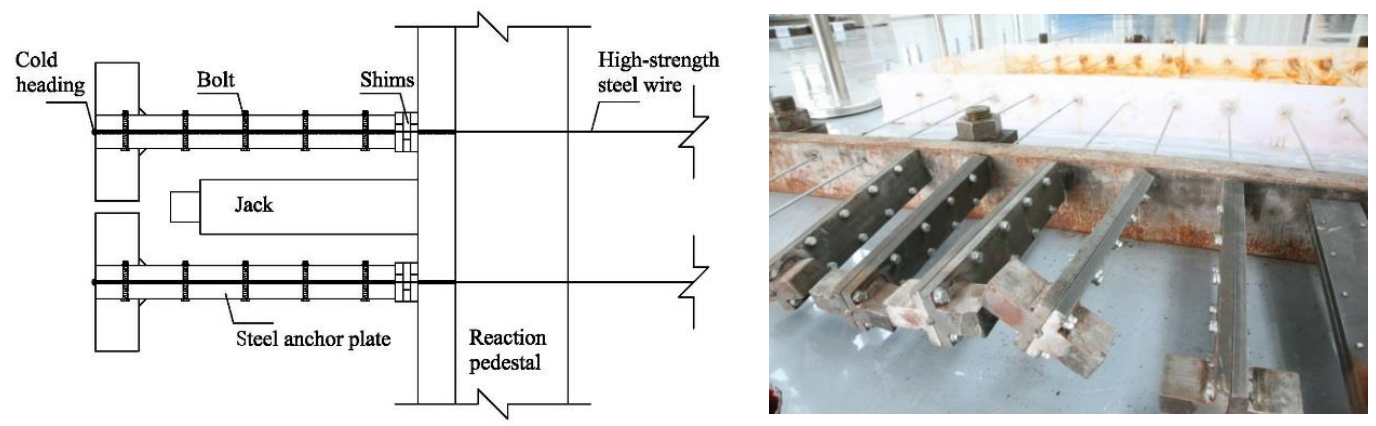

(a)

Figure 3. Cont. 

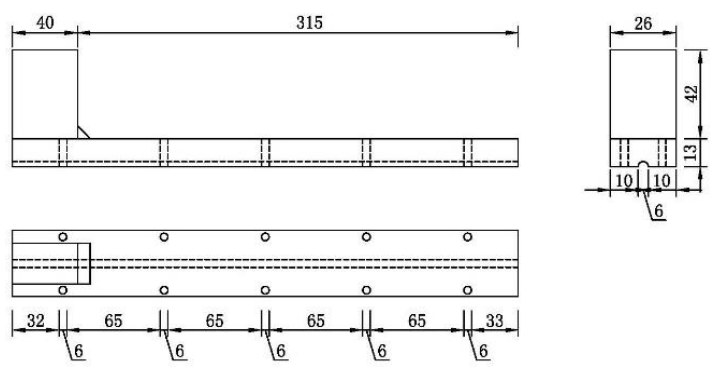

(b)

Figure 3. Front strain-holding part of the test device: (a) front strain-holding part; (b) anchorage plate (unit: $\mathrm{mm}$ ).
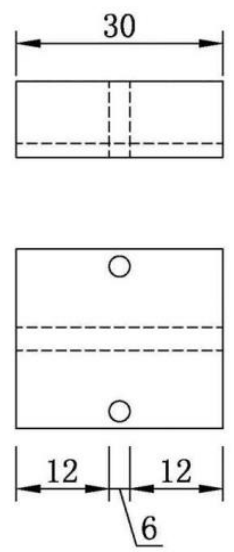

(a)
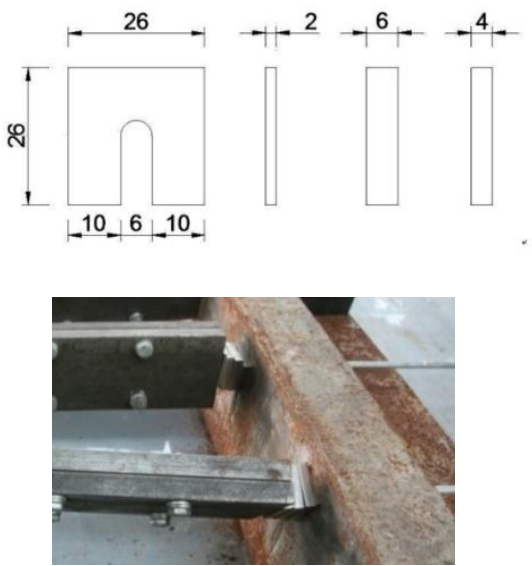

(b)

Figure 4. Back strain-holding part of the test device: (a) back strain-holding part (unit: $\mathrm{mm}$ ); (b) shims (unit: $\mathrm{mm}$ ).

\subsection{Electrochemical Accelerated Corrosion Test and Static Tensile Test}

High-strength steel wires were subject to different strains using the above-described strain-holding device that transfers the applied force to the ground anchor by a steel reaction pedestal. The corrosion tank was designed as a semi-closed solution tank containing a $5 \% \mathrm{NaCl}$ electrolyte. To prevent sodium chloride solution from leaking and affecting the corrosion process, ABS plexiglass was selected as a substrate, and glass glue was reinforced in the gap. Figure 5 shows the current loop of the accelerated corrosion test. At the anode, all the steel wires passing through the reaction pedestal were connected in parallel in the circuit. At the cathode, the current was output to the two uniform aluminum plates.

All specimens underwent an electrochemical accelerated corrosion test using the strain-holding device. After each batch of accelerated corrosion, in accordance with the "Standard for test method of long term performance and durability of ordinary concrete (GB/T 50082-2009)", the wire specimens were pickled with a $12 \%$ hydrochloric acid solution, followed by rinsing in clean water. The specimens were then neutralized with $\mathrm{Ca}(\mathrm{OH})_{2}$ solution and rinsed again. After drying, they were stored in a desiccator for at least $4 \mathrm{~h}$. A $50-\mathrm{cm}$ corroded segment in the middle of the specimen was measured to identify the corrosion degree.

The static tensile test was conducted on high-strength wire specimens using a servo-hydraulic testing machine (MTS Systems Corporation, Shanghai, China) and strain-control loading was applied, as shown in Figure 6. 


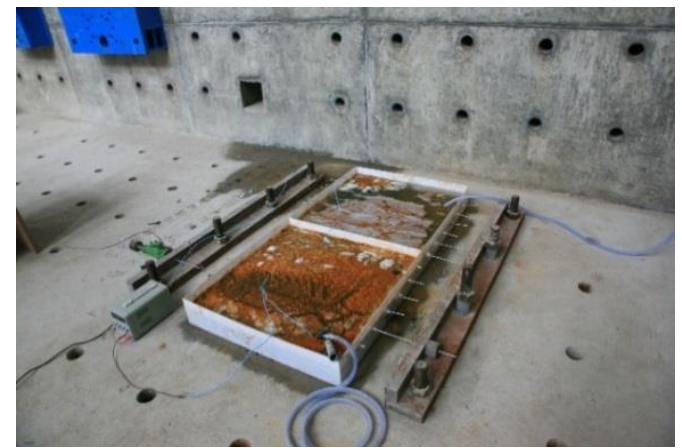

Figure 5. Electrochemical accelerated corrosion experiment.

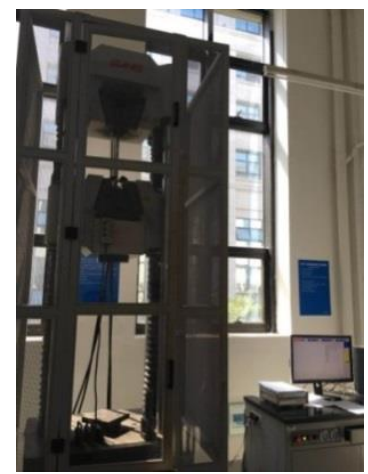

Figure 6. Static tensile testing of corroded wire.

\section{Analysis of Experimental Results}

\subsection{Morphology of Corroded Steel Wires}

Figure 7 shows the morphology of corroded steel wires under different corrosion times and strain levels. High-strength steel wires under strain of $2000 \mu \varepsilon$ gradually displayed zinc leaching from their galvanized coating, precipitation of dark-brown corrosion products, and enlargement of the corrosion area with increase in accelerated corrosion days. After accelerating the corrosion for three days, the corrosion products of steel wires under low strain levels were uniformly distributed in a longitudinal direction; however, products exposed to high strain levels displayed more severe corrosion and smaller nominal diameters.

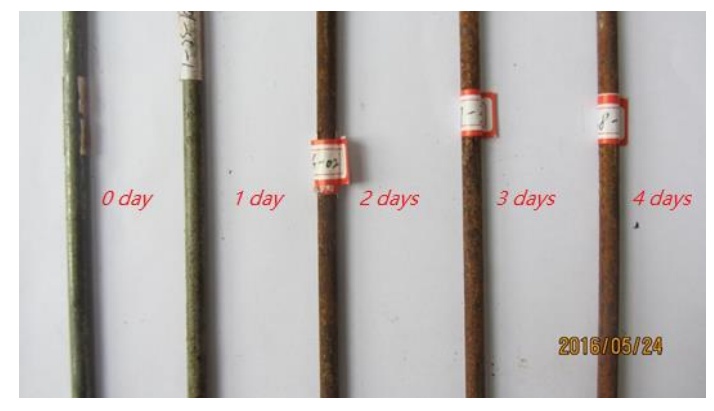

(a)

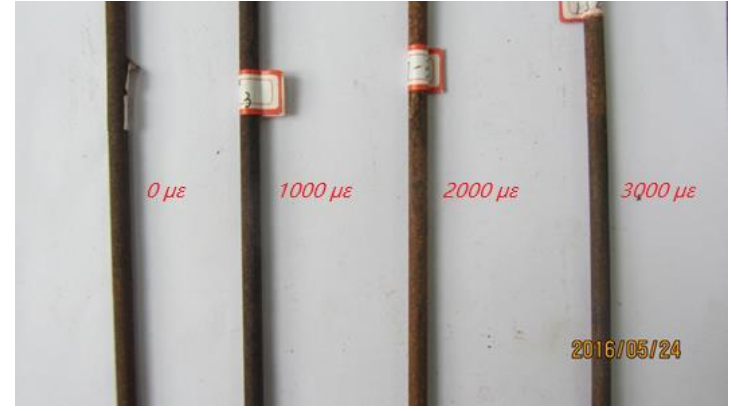

(b)

Figure 7. Corrosion shapes of cable wires: (a) Time-varying corrosion (at $2000 \mu \varepsilon$ strain); (b) strainvarying corrosion (on the third day).

In order to obtain more details of the morphology of corroded steel wire, high-strength steel wires were scanned using ultra-depth 3D microscopic imaging technology. The localized corrosion 
properties of high-strength steel wire with a macroscopic curvature cannot be accurately scanned in low magnification. Under high magnification, the depth from defocus (DFD) technology was used to deal with problems such as image edge shift and magnification fluctuation caused by focal length changes. The experiment found that magnifications of $500 \times$ and $1000 \times$ are decent enough to ensure observation of the morphology of the corroded surfaces of steel wire. A study under $500 \times$ magnification revealed that the surface morphology of the un-corroded steel wire was under $0 \mu \varepsilon$, and that of the corroded steel wires was $1000 \mu \varepsilon$ and $2000 \mu \varepsilon$ strains, respectively, after accelerated corrosion for one day (Figure 8). These results illustrate that the surface of the un-corroded steel wire had a well-preserved anti-corrosion coating and no exposed base material; several active corrosion pits are observed from the microscope image. In the case of the high-strength steel wire after accelerated corrosion under $1000 \mu \varepsilon$ strain for one day, the surface morphology was basically the same as that of the un-corroded wire, except that the number of active corrosion pits greatly increased and surface roughness was more prominent. For the high-strength steel wire after accelerated corrosion under $2000 \mu \varepsilon$ strain for one day, the corrosion products were obviously increased and the base material near the active corrosion pits showed outward precipitation, forming a contour of pitting corrosion.

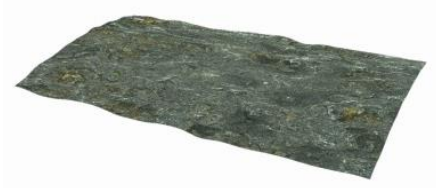

(a)

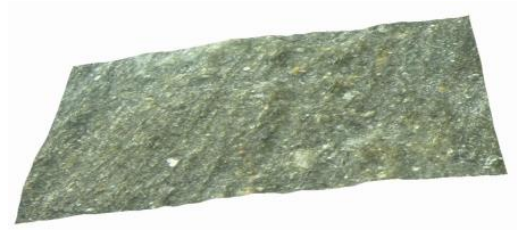

(b)

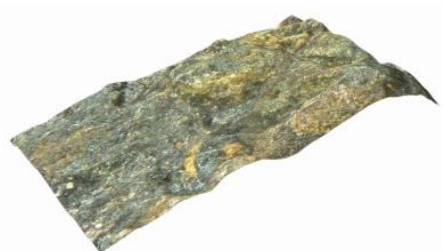

(c)

Figure 8. Comparison of the surface morphology after 1 day corrosion using ultra-depth 3D microscope with magnification of 500X: (a) $0 \mu \varepsilon$; (b) $1000 \mu \varepsilon$; (c) $2000 \mu \varepsilon$.

Figure 9 shows the morphology of the high-strength steel wire with increasing corrosion time at $2000 \mu \varepsilon$ strain. It can be seen that the longer the corrosion time, the more severe the pitting on the surface of the steel wire was.

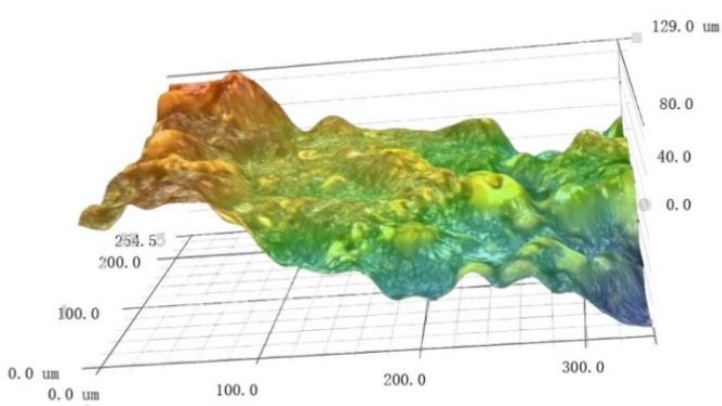

(a)

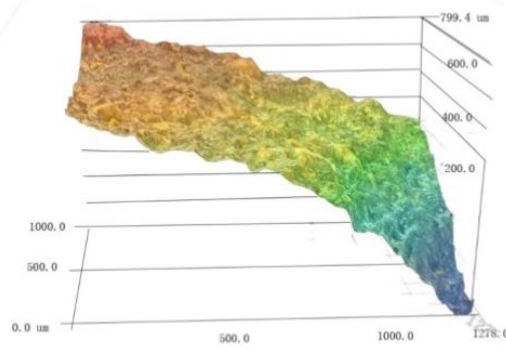

(b)

Figure 9. Comparison of the surface morphology under $2000 \mu \varepsilon$ strain: (a) accelerated corrosion for two days; (b) accelerated corrosion for four days.

\subsection{Mass Loss Ratio and Sectional Diameter of Corroded Steel Wire}

In order to quantitatively analyze the corrosion degree of the steel wires after accelerated corrosion, the corrosion of the high-strength steel wires was measured in terms of mass loss rate and minimum diameter of the section. By weighing specimens before and after the corrosion, the mass loss rate of the high-strength steel wires was obtained according to the following formula:

$$
\eta=\frac{m_{0}-m_{1}-m_{2}}{m_{0}-m_{1}} \times 100 \%
$$


where $m_{0}$ is the wire weight before corrosion, $m_{1}$ and $m_{2}$ are the weights of the un-corroded segment and corroded segment of the rust-cleaning wire after the accelerated corrosion test, respectively. Table 2 shows the average mass loss rate of specimens under each specific strain and corrosion time. The tendency of the corrosion degree, as shown in Figure 10, shows that the average mass loss rate of steel wire increases nonlinearly with time and the corrosion rates have a faster-growing trend. It also illustrates that the higher the strain level, the more severe is the corrosion. On one hand, high-strength steel wires with high strain levels causes the substrate defects generated by pitting corrosion to stretch and expand continuously during the corrosion process, resulting in faster corrosion in a higher-strain steel wire. On the other hand, the high-strain state decreases the electrical resistance of the steel wire; when the external electrochemical potential is constant, it strengthens current density and intensifies the corrosion.

Table 2. Mass loss rate of corroded cable wires.

\begin{tabular}{ccccc}
\hline Strain Level & 1 Day & 2 Day & 3 Day & 4 Day \\
\hline $0 \mu \varepsilon$ & $1.10 \%$ & $2.31 \%$ & $4.83 \%$ & $8.45 \%$ \\
\hline $1000 \mu \varepsilon$ & $1.23 \%$ & $4.03 \%$ & $5.81 \%$ & $8.73 \%$ \\
\hline $2000 \mu \varepsilon$ & $3.77 \%$ & $5.39 \%$ & $6.67 \%$ & $9.33 \%$ \\
\hline $3000 \mu \varepsilon$ & $4.40 \%$ & $6.59 \%$ & $15.12 \%$ & $28.14 \%$ \\
\hline
\end{tabular}

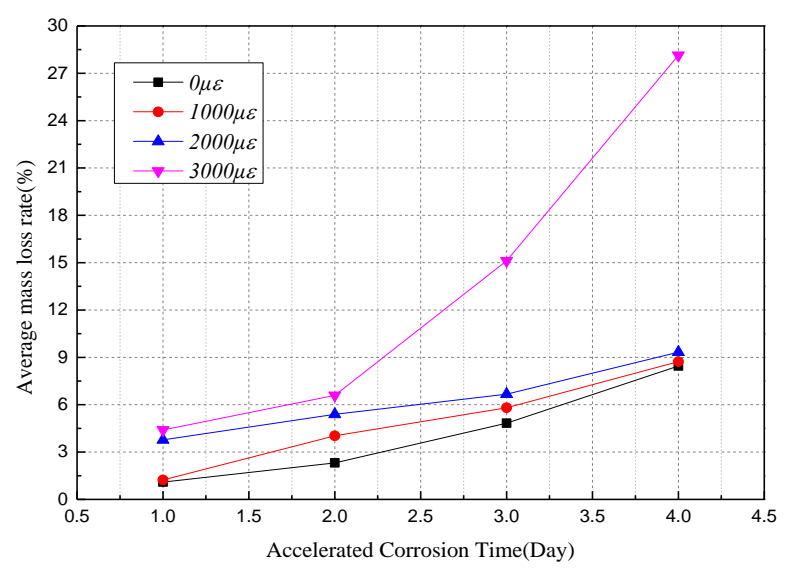

Figure 10. Average mass loss rates of steel wires under variable corrosion times and strains levels.

The corrosion of high-strength steel wire is normally not uniformly-distributed in a longitudinal direction. It may give rise to localized corrosion, the degree of which can be estimated indirectly by measuring the minimum diameter $d_{\min }$ with a vernier caliper. Thereby, the minimum diameter $d_{\min }$ of the wire section can be used as an index to measure the degree of pitting corrosion.

Figure 11a shows that the minimum diameter of the steel wires under different strain levels tends to decrease when the corrosion time increases. On the first couple of days, the curve tends to fluctuate, due to the influence of coating on the corrosion. Then, the reduction of the minimum diameter shows a non-linear growth rate. For specimens that were accelerated at a certain corrosion time, the minimum diameter of the steel wire was fitted to a linear function of strain, as shown in Figure 11b. This illustrates a good linear relationship between the minimum cross-sectional diameter and the applied strain, and the longer the time, the great the corrosion rate. 


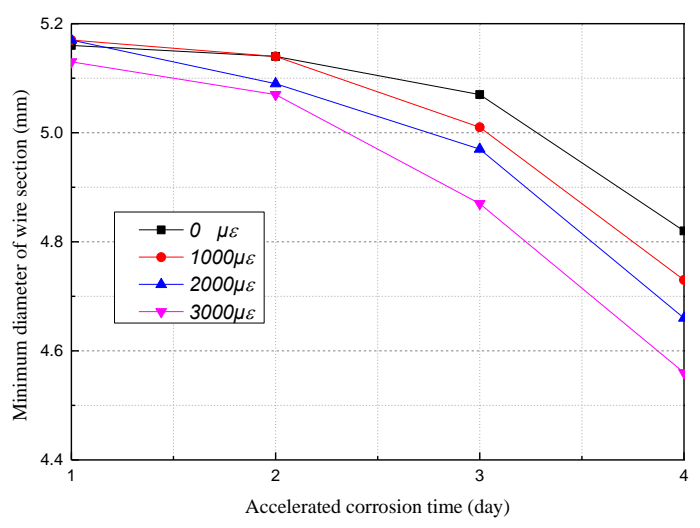

(a)

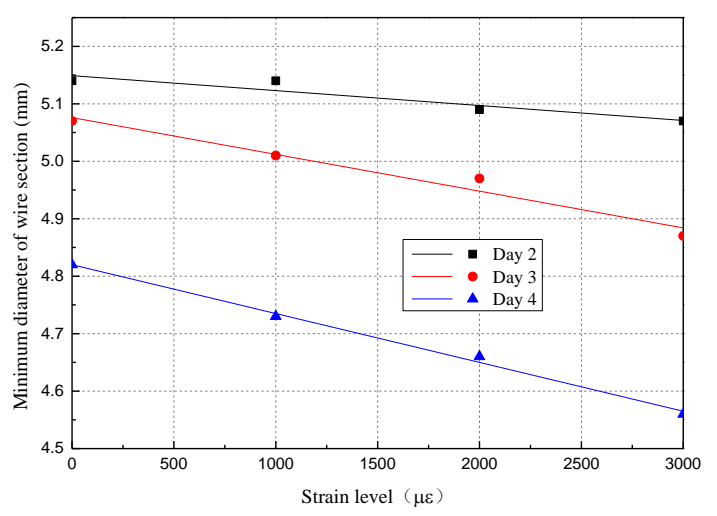

(b)

Figure 11. Curve of minimum diameter with corrosion time and strain level: (a) Minimum diameter over corrosion time; (b) minimum diameter over strain levels.

\subsection{Mechanical Properties of Corroded Wires}

Figure 12 shows the results of the mechanical properties of the corroded wires subject to tensile tests. Based on the curve of tensile force and elongation, the yield loads of high-strength wires under small strain levels change slightly with the increasing corrosion time; however, it has an obvious variation of yield loads at $2000 \mu \varepsilon$ and $3000 \mu \varepsilon$ strain levels. The ultimate load and ultimate elongation of high-strength wires under the same strain level decrease with corrosion time, indicating a deterioration of the mechanical behavior of such wires due to the corrosion. According to Table 3, the yield load and ultimate load of steel wires present different levels of decline, when compared with the four applied strain levels. The result shows an obvious decline of cable wire strength under high strain levels.

The stress of the main cable wire in an actual suspension bridge is approximately $500 \mathrm{MPa}$ to $600 \mathrm{MPa}$, which is about a strain of $3000 \mu \varepsilon$. In Figure 12d, the slopes of the force-elongation curves corresponding to corrosion-for days 1 to 4 are $6.845,5.891,5.526$, and 5.174, respectively, which when converted to the ratio of the elastic modulus is $100 \%, 91.56 \%, 94.97 \%$, and $98.89 \%$. This implies that the modulus of elasticity of corroded steel wires does not change significantly with increase of corrosion time. 


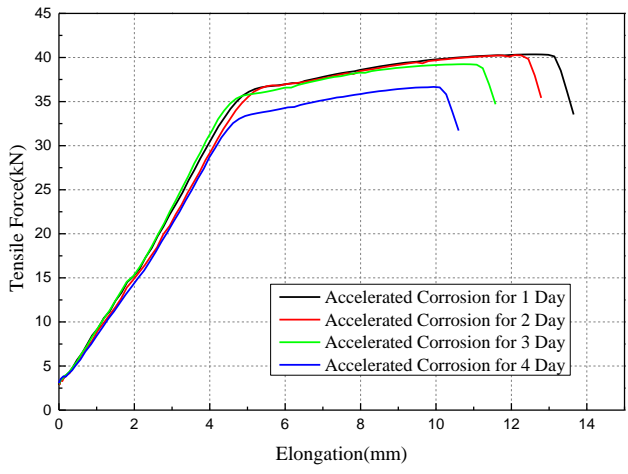

(a)

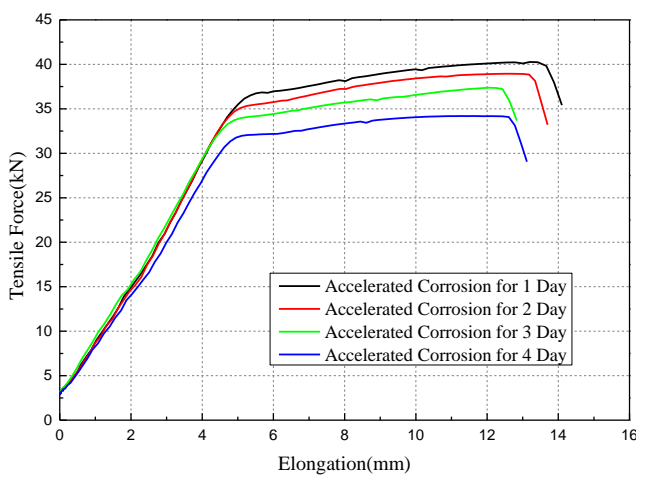

(c)

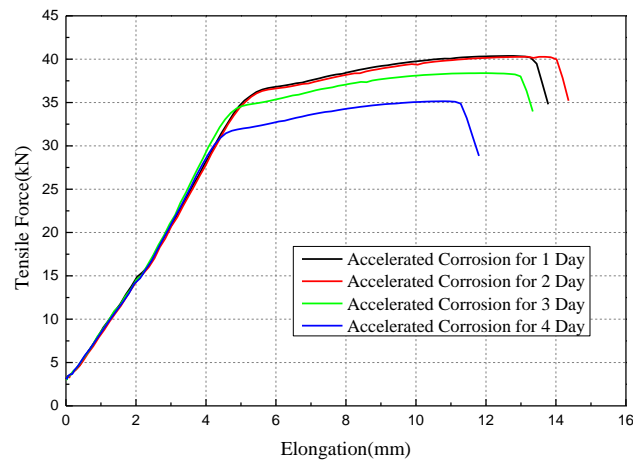

(b)

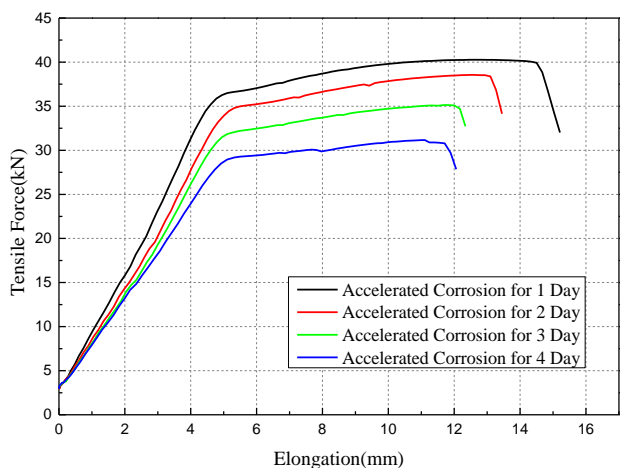

(d)

Figure 12. Force-elongation curve of corroded wires: (a) Under the strain of $0 \mu \varepsilon$; (b) under the strain of $1000 \mu \varepsilon ;$ (c) under the strain of $2000 \mu \varepsilon ;(d)$ under the strain of $3000 \mu \varepsilon$.

Table 3. Mechanical property of corroded cable wires.

\begin{tabular}{cccccc}
\hline Mechanical Property & Strain Level & 1 Day & 2 Day & 3 Day & 4 Day \\
\hline \multirow{3}{*}{ Yield Load $(\mathrm{kN})$} & $0 \mu \varepsilon$ & 38.65 & 37.63 & 37.11 & 36.43 \\
\cline { 2 - 6 } & $1000 \mu \varepsilon$ & 38.47 & 37.63 & 36.28 & 35.47 \\
\cline { 2 - 6 } & $2000 \mu \varepsilon$ & 38.32 & 37.09 & 36.86 & 35.22 \\
\cline { 2 - 6 } & $3000 \mu \varepsilon$ & 37.74 & 37.23 & 35.04 & 31.55 \\
\cline { 2 - 6 } & $0 \mu \varepsilon$ & 40.24 & 39.22 & 38.46 & 36.88 \\
\cline { 2 - 6 } Ultimate Load $(\mathrm{kN})$ & $1000 \mu \varepsilon$ & 40.18 & 38.95 & 38.12 & 36.91 \\
\cline { 2 - 6 } & $2000 \mu \varepsilon$ & 40.17 & 38.89 & 38.06 & 36.35 \\
\hline
\end{tabular}

\section{Correlation Analysis between Corrosion Degree and Mechanical Properties of Cable Wires under Constant Strains}

\subsection{Tensile Behavior with the Average Mass Loss Rate}

According to Tables 2 and 3, the mechanical properties of corroded steel wires are presented in Figure 13 with respect to mass loss rate. It can be seen that, as the average mass loss rate increases, the tensile behavior of the specimens decreases. By fitting the test data, the yield load and ultimate load can be expressed as:

$$
p_{y}=38.53-25.68 \cdot \eta
$$




$$
p_{u}=40.18-27.86 \cdot \eta
$$

where $p_{y}$ and $p_{u}$ are the yield load and ultimate load of high-strength steel wire, and $\eta$ is mass loss rate of high-strength steel wires. The root mean squared error of the yield load is 0.5015 , while the ultimate load produces an error of 0.7069 . The ratio of yield load and ultimate load of corroded steel wires, applied to those of the non-corroded ones, can be obtained from Equations (2)-(3):

$$
\begin{aligned}
& \alpha_{y}=1-0.666 \cdot \eta \\
& \alpha_{u}=1-0.693 \cdot \eta
\end{aligned}
$$

where $\alpha_{\mathrm{y}}$ and $\alpha_{\mathrm{u}}$ are the ratios for yield load and ultimate load. However, when compared with the test result in Reference $[25,28,29]$, the slopes of the ratio, as shown in Table 4 , are widely divergent, induced by the type of steel bars.

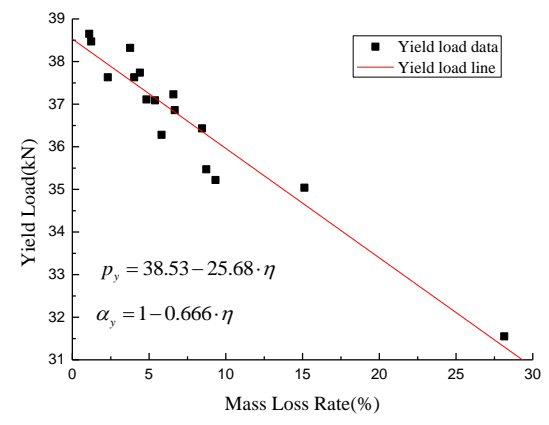

(a)

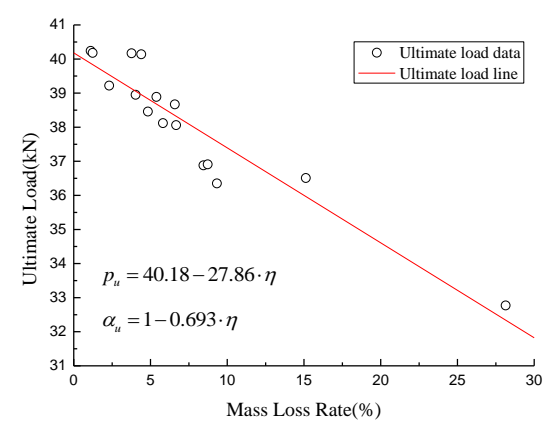

(b)

Figure 13. Mechanical properties of the specimens: (a) Yield load; (b) ultimate load.

Table 4. Comparison of the ratio of yield load and ultimate load.

\begin{tabular}{ccccc}
\hline Researcher & Bar Type & Diameter/mm & Yield Load & Ultimate Load \\
\hline Authors & Steel Wire & 5.25 & $\alpha_{y}=1-0.666 \cdot \eta$ & $\alpha_{u}=1-0.693 \cdot \eta$ \\
\hline Wu et al. [28] & Steel Bar & 16 & $\alpha_{y}=1-1.625 \cdot \eta$ & $\alpha_{u}=1-1.775 \cdot \eta$ \\
\hline Zhang et al. [29] & Bar in Concrete & 6.5 & $\alpha_{y}=1-12 \cdot \eta$ & $\alpha_{u}=1-1.36 \cdot \eta$ \\
\hline Li et al. [25] & Steel Strand & 15.20 & - & $\alpha_{u}=1-2.683 \cdot \eta$ \\
\hline
\end{tabular}

\subsection{Tensile Behavior with the Minimum Diameter of the Section}

From Figures 10 and 11, it can be seen that strain has a significant influence on the corrosion degree of high-strength cable wires, especially under the combined effect of uniform corrosion and localized pitting. Moreover, the change in the minimum diameter of the steel wire section can fairly describe the corrosion status. On the basis of polynomial regression analysis, the relationship between the minimum diameter and the corrosion influence factors is regressed, and the formula of the minimum cross-sectional diameter of steel wires under a specific strain is derived as follows:

$$
d_{\min }=\left(4.746+0.3845 t-0.0915 t^{2}\right)+\left(101-80.5 t+8.5 t^{2}\right) \cdot \varepsilon / 10^{6}
$$

where $d_{\min }$ is the minimum diameter of steel wire, $t$ is the corrosion time in the test (unit: day) and $\varepsilon$ is the constant stain applied to the steel wire (unit: $\mu \varepsilon$ ).

Figure 14 shows the fitting result of specimens to the minimum diameter on the yield load of steel wire. The Pearson coefficient between the two parameters is 0.8427 . In the initial stages of corrosion, the minimum diameter of the section is linear with the yield force. In the later stages of 
corrosion, however, the micro-cracks caused by pitting gives rise to discreteness of the data. The linear relationship between the minimum diameter and the yield load of steel wires can be expressed as:

$$
p_{y}=7.191 d_{\min }+0.855
$$

Then, by substituting the fitting expression (6), the variation of the yield force with the corrosion time can be obtained at a certain strain level:

$$
p_{y}=\left(34.98+2.77 t-0.66 t^{2}\right)+\left(7.26-5.79 t+0.61 t^{2}\right) \cdot \varepsilon / 10^{4}
$$

The test data of the yield load is classified according to different strain levels, and the correlation of strain effect on the yield load is obtained, as shown in Figure 15. The slopes of the regression lines at the four strain levels are almost the same. In other words, the strain level only affects the minimum diameter of the section during the corrosion process, but has little effect on the decline rate of the yield load.

It is worth noting that due to the concentration of corrosion in the wire section caused by high strain and localized pitting, the critical parameter related to the propagation of corrosion cracking is the minimum diameter of the section, rather than the mass loss rate, especially in the scenario of high strain and long-term corrosion. Therefore, it is unreliable to use the nominal diameter of the steel wire to calculate yield strength, and the data will be scattered as corrosion time increases.

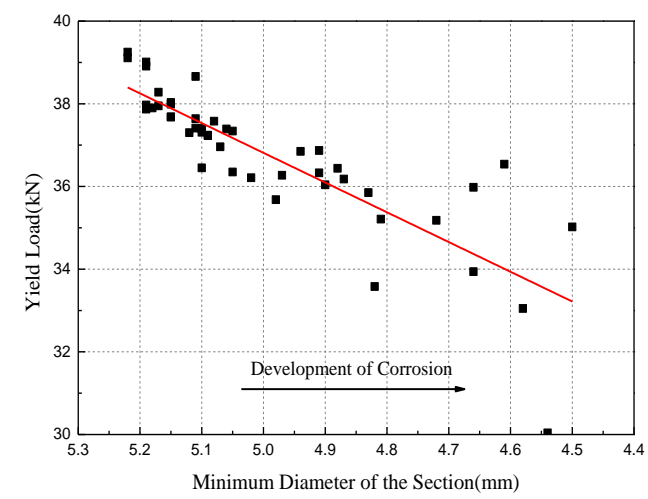

Figure 14. Variation of yield load versus minimum diameter.

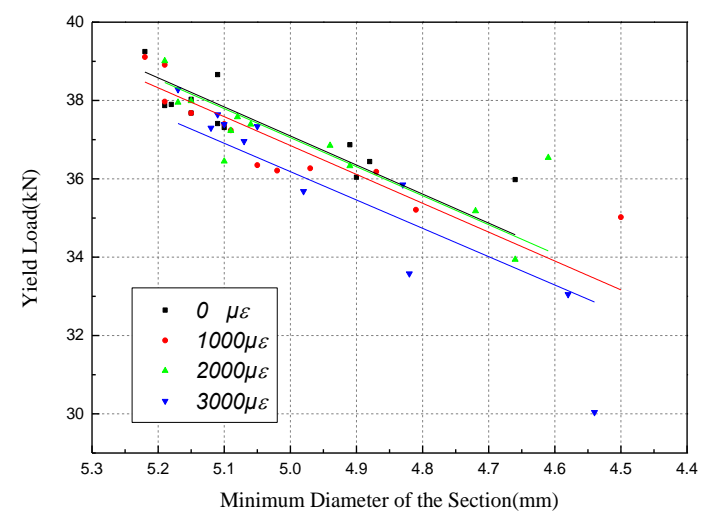

Figure 15. Correlation of minimum diameter and yield load for different strain levels. 
Similar results can be found for the relationship between minimum diameter and ultimate load, as shown in Figure 16. The Pearson coefficient between the two parameters is 0.8605 , and the regression formula is given as:

$$
p_{u}=8.148 d_{\min }-2.429
$$

Then, the variation of the ultimate force with corrosion time can be obtained at a certain strain level:

$$
p_{u}=\left(36.24+3.13 t-0.75 t^{2}\right)+\left(8.23-6.56 t+0.693 t^{2}\right) \cdot \varepsilon / 10^{4}
$$

Based on Figure 17, the slope of the ultimate force versus the minimum diameter remains the same as the strain level increases. That is to say, the strain level has little effect on the ultimate force with the deceleration rate of the minimum diameter.

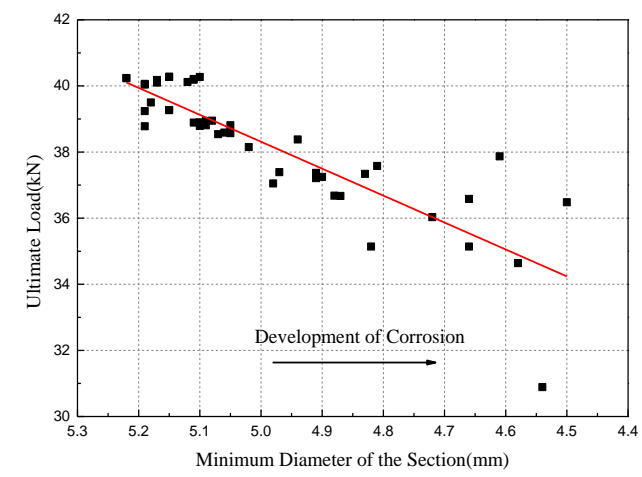

Figure 16. Variation of ultimate load versus minimum diameter.

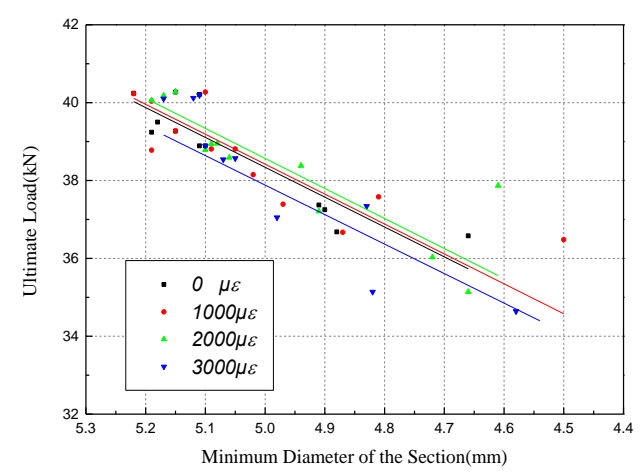

Figure 17. Correlation of minimum diameter and ultimate load for different strain levels.

\section{Conclusions}

This paper presents an experimental study on the corrosion of cable wires considering the effect of strain. The main conclusions are:

(1) A precise strain-holding device was designed, which changed the conventional way of force loading in the accelerated corrosion test. By jamming the button head, constant strain was applied to the steel wire by a hydraulic jack and steel shims. The corrosion of steel wires under different strain levels and corrosion times was obtained; the test result shows that the corroded product and corrosion morphology are different from ordinary steel bars. The longer the corrosion time, the larger the corrosion area. The diameter of the wire decreases at a non-linear rate as corrosion time increases.

(2) A statistical analysis of the average mass loss rate and the minimum diameter of the wire section was carried out with respect to the strain level and corrosion time. This illustrates that the minimum diameter of the high-strength steel wire section has a linear correlation with the applied strain level, which can be used as a measure of corrosion degree. 
(3) Based on linear fitting for tensile behavior, yield load and ultimate load can be expressed in terms of the mass loss rate of high-strength steel wires. However, when compared with the references, the slopes of the ratio of yield load and ultimate load of corroded steel wires to those of the non-corroded ones are widely divergent.

(4) A statistical regression analysis was carried out to obtain the expression of minimum diameter with various strain levels and corrosion time. Then, variation of the yield load and ultimate load was given with corrosion time and strain level. The result shows that stress level affects the minimum diameter of the section during the corrosion process, which indirectly reduces the yield load.

Author Contributions: F.X. initiated the research and designed the experiments; Y.C. and X.Z. investigated and analyzed the experiments; R.M. offered advice and supervision; F.X. and H.T. wrote the paper.

Funding: This research was funded by Basic Public Welfare Research Project of Zhejiang Province, grant number LGF18E080002, and Natural Science Foundation of Zhejiang Province, grant number LY18E080002.

Conflicts of Interest: The authors declare no conflict of interest.

\section{References}

1. Wang, G. Corrosion and Protection under Natural Environment; Chemical Industry Press: Beijing, China, 1997.

2. Eriksson, P.; Carlsson, B.; Wallinder, I.O. Design of accelerated corrosion tests for electronic components in automotive applications. IEEE Trans. Compon. Packag. Technol. 2001, 24, 99-107. [CrossRef]

3. Zeng, Y.; Gu, X.; Zhang, W.; Huang, Q. Accelerated corrosion technique for reinforcement steel bars in concrete. J. Struct. Eng. 2009, 25, 101-105.

4. Xia, J. Mechanical Behavior of Corroded Reinforced Concrete Structure. Ph.D. Thesis, Zhejiang University, Hangzhou, China, 2010.

5. Chen, X. Experimental analysis of a non-destructive corrosion monitoring system for main cables of suspension bridges. J. China Foreign Highw. 2016, 36, 72-76.

6. Suzumura, K.; Nakamura, S. Environmental factors affecting corrosion of galvanized steel wires. J. Mater. Civ. Eng. 2004, 16, 1-7. [CrossRef]

7. Li, X.; Dong, C.; Xiao, K.; Du, C.; Zhou, H.; Lin, C. Initial Behavior and Mechanism of Metal Atmospheric Corrosion; Science Press: Beijing, China, 2009.

8. Miao, C.; Sun, C.; Chen, L. Research on equivalent conversion method of environmental corrosion for cable components of large span bridges. J. Water Resour. Archit. Eng. 2010, 8, 5-7.

9. Li, X.; Liu, Q.; Kong, L.; Zhou, J. Corrosion behavior of galvanized steel under stress in simulated acid rain solution. Corros. Sci. Prot. Technol. 2008, 20, 44-46.

10. Betti, R.; West, A.; Vermaas, G.; Cao, Y. Corrosion and embrittlement in high-strength wires of suspension bridge cables. J. Bridge Eng. 2005, 10, 151-162. [CrossRef]

11. Barton, S.C.; Vermaas, G.W.; Duby, P.F.; Alan, C.V.; Betti, R. Accelerated corrosion and embrittlement of high-strength bridge wire. J. Mater. Civ. Eng. 2000, 12, 33-38. [CrossRef]

12. Nakamura, S.; Suzumura, K.; Taruit, T. Mechanical properties and remaining strength of corroded bridge wires. Struct. Eng. Int. 2004, 14, 50-54. [CrossRef]

13. Nakamura, S.; Suzumura, K. Hydrogen embrittlement and corrosion fatigue of corroded bridge wires. J. Constr. Steel Res. 2009, 65, 269-277. [CrossRef]

14. Li, X.-M.; Zhou, J.; Liu, Q.; Kong, L.-F.; Zhou, J. Effect of tension on corrosion behavior of galvanized steel wire for cable-Stayed bridge. Electrochemistry 2007, 13, 297-304.

15. Yang, W.J.; Yang, P.; Li, X.M.; Feng, W.L. Influence of tensile stress on corrosion behavior of high-strength galvanized steel bridge wires in simulated acid rain. Mater. Corros. 2012, 63, 401-408. [CrossRef]

16. Wu, S.; Chen, H.; Ramandi, H.L.; Hagan, P.C.; Crosky, A.; Saydam, S. Effects of environmental factors on stress corrosion cracing of cold-drawn high-carbon steel wires. Corros. Sci. 2018, 132, 234-243. [CrossRef]

17. Melchers, R.E. Statistical characterization of pitting corrosion part 1: Data analysis. Corrosion 2005, 61, 655-664. [CrossRef]

18. Paik, J.K.; Lee, J.M.; Ko, M.J. Ultimate compressive strength of plate elements with pit corrosion wastage. J. Eng. Marit. Environ. 2003, 217, 185-200. [CrossRef] 
19. Mao, J.; Xu, F.; Jin, W.; Gao, Q.; Xu, Y.; Xu, C. An optical fiber sensor method for simultaneously monitoring corrosion and structural strain induced by loading. J. Test. Eval. 2018, 46, 1443-1451. [CrossRef]

20. Li, X.; Li, D. Wavelet analysis and evaluation of ultrasonic guided wave signal on corrosion damage for reinforced concrete. Prestress Tech. 2014, 2, 20-23.

21. Zhang, W.; Li, S.; Gu, X.; Zhu, C. Experiment on axial tensile fatigue of naturally corroded steel bar. China J. Highw. Transp. 2009, 22, 53-58.

22. Ramandi, H.L.; Chen, H.; Crosky, A.; Saydam, S. Interactions of stress corrosion cracks in cold drawn pearlitic steel wires: An X-ray micro-computed tomography study. Corros. Sci. 2018, 145, 170-179. [CrossRef]

23. Vehovar, L.; Kuhar, V.; Vehovar, A. Hydrogen-assisted stress-corrosion of prestressing wires in a motorway viaduct. In Engineering Failure Analysis; Elsevier: Amsterdam, The Netherlands, 1998; Volume 5, pp. 21-27.

24. Liu, W.; Li, W.; Ma, Q. Corrosion test of high strength steel wire strand in marine environment. HVM Prestress. Technol. 2001, 2, 34-38.

25. Li, F.; Yuan, Y.; Du, J.; Ma, H. Deterioration of tensile behavior of steel strands corroded by chloride. J. Southeast Univ. 2009, 39, 340-344.

26. Zheng, Y.; Ou, Y.; An, L. Study on the test of mechanical properties of corroded steel bar embedded in concrete. Mod. Transp. Technol. 2005, 2, 33-36.

27. Zhang, H.; Zhang, L.; Hu, S.; Zhang, J.; Hu, D. The effect of chloride salt corrosion on deterioration of loaded steel strands. Sci. Tech. Eng. 2018, 18, 232-236.

28. Wu, X.; Li, L.; Li, H.; Li, B.; Ling, Z. Effect of strain level on corrosion of stainless steel bar. Construc. Build. Mater. 2018, 163, 189-199. [CrossRef]

29. Zhang, W.; Song, X.; Gu, X.; Li, S. Tensile and fatigue behavior of corroded rebars. Construc. Build. Mater. 2012, 34, 409-417. [CrossRef]

(C) 2019 by the authors. Licensee MDPI, Basel, Switzerland. This article is an open access article distributed under the terms and conditions of the Creative Commons Attribution (CC BY) license (http:/ / creativecommons.org/licenses/by/4.0/). 